\title{
Factors related to cancer screening behaviors
}

\author{
Boyoung Choi', Tae Rim Um², Kwang-Soo Lee ${ }^{3}$ \\ ${ }^{1}$ Department of Public Health and Medical Administration, Dongyang University, Yeongju, Korea; ${ }^{2}$ Department of Health Administration, Yonsei \\ University Graduate School, Wonju, Korea; ${ }^{3}$ Department of Health Administration, Yonsei University College of Health Sciences, Wonju, Korea
}

OBJECTIVES: This study aimed to investigate the factors related to cancer screening behaviors (CSB).

METHODS: The 2014 Korean Community Health Survey used for analysis. The dependent variable was CSB, and the independent variables were demographic, health behavioral, and regional factor. Propensity score matching (PSM) used to control health behavior and regional factors, which were influencing CSB. For statistical analysis, chi-square test and logistic regression analysis used.

RESULTS: Logistic regression analysis after PSM showed that gender, age, marital status, educational level, monthly household income, employment type, alcohol drinking, smoking, body mass index group, chronic disease, and subjective health status influenced the CSB, there were statistical differences.

CONCLUSIONS: To improve cancer screening (CS), it is necessary to educate individuals on the need for CS and to carry out a personalized CS program based on an individual's demographic status and health behavior.

KEY WORDS: Early detection of cancer, Demography, Propensity score, Korean Community Health Survey

\section{INTRODUCTION}

Cancer is a disease responsible for millions of deaths worldwide. According to the World Health Organization (WHO) [1], 14 million people died of cancer in 2012. In Korea, the incidence has reached 250 per 100,000 population since 2008 [2], with 79,000 cancer-related deaths reported in 2016 [3]. As of 2016, the number of cancer-related deaths per 100,000 population by cancer types, in descending order, was lung cancer $(n=52.2)$, liver cancer $(n=31.5)$, and gastric cancer $(n=20.8)$ among men and lung cancer $(n=18.1)$, colon cancer $(n=14.6)$, and liver cancer $(n=11.6)$ among women [4].

The onset of cancer causes physical and mental suffering in the

\section{Correspondence: Kwang-Soo Lee}

Department of Health Administration, Yonsei University College of Health Sciences, 1 Yonsedae-gil, Wonju 26493, Korea

E-mail: planters@yonsei.ac.kr

Received: Jan 29, 2018 / Accepted: Mar 29, 2018 / Published: Mar 29, 2018

This article is available from: http://e-epih.org/

(C) This is an open-access article distributed under the terms of the Creative Commons Attribution License (http://creativecommons.org/licenses/by/4.0/), which permits unrestricted use, distribution, and reproduction in any medium, provided the original work is properly cited.

(C) 2018, Korean Society of Epidemiology patient and their family, while increasing economic burden. From a national perspective, it causes economic losses due to loss of human resources and decreased productivity, increasing national healthcare expenditure [5].

Cancer treatment outcome varies significantly by cancer stage. The 5-year relative survival rate (RSR) for major cancers (gastric, colorectal, breast, cervical, prostate, and thyroid cancers), excluding lung cancer, is approximately $90.0-100.0 \%$ when the cancer is localized to a single organ. However, in cases of distant metastasis, the 5-year RSR for major cancers, excluding thyroid cancer, is only 5.5-36.4\% [6]. As shown, the treatment effect of cancer can link directly to early detection of cancer.

The WHO reported that prevention of cancer is possible through changes in dietary habits and lifestyle, while the distress by cancer can reduce through early cancer detection, accurate diagnosis and effective treatment [7]. Primary prevention through changes in lifestyle are difficult since it relies on each individual. Therefore, it is important to utilize cancer screening (CS), a secondary prevention, to seek early cancer detection. For this, most countries have implemented national CS programs, while also using various promotional efforts for early cancer detection. In Korea, two type of national CS programs have for low-income families and the five major cancers for civilian. Additionally, CS is also offered by private insurance companies, meaning CS is available in various ways [8]. 
However, despite various nationwide efforts in promoting such programs, the rate of participation in the national CS for gastric, liver, colorectal, breast, and cervical cancer in Korea was only 45.3, $43.9,32.9,49.0$, and 40.5\%, respectively, in 2011 [9]. Various studies have followed to identify the reasons for such low CS participation rate. CS-related studies can divide into two major categories: (1) studies on the individual respondents that examined the cancer screening behaviors (CSB) $[8,10]$ and specific CS rates [11-13] and (2) studies on environmental factors that examined the health screening behaviors of individuals in the urban versus rural settings [14]. However, most studies examined a specific cancer or region, which makes it difficult to identify the factors associated with overall CS for the entire population of Korea. To increase the rate of participation in CS, it is important to identify not only the environmental and health behavior factors that influence CS, but also the CS-related demographic characteristics of each individual to provide cancer education and screening services that are customized by various characteristics and social classes.

Accordingly, this study aimed to identify the demographic characteristics that show differences in CSB in presenting the basic data that can help increase the rate of participation in CS. For the more objective analysis of CSB, this study used propensity score matching (PSM) of the confounding factors such as health behavioral and regional factors.

\section{MATERIALS AND METHODS}

\section{Research model}

Figure 1 shows the model used in this study. Analysis performed with the demographic, health behavior, and regional characteristics as independent variables and CSB as the dependent variable.

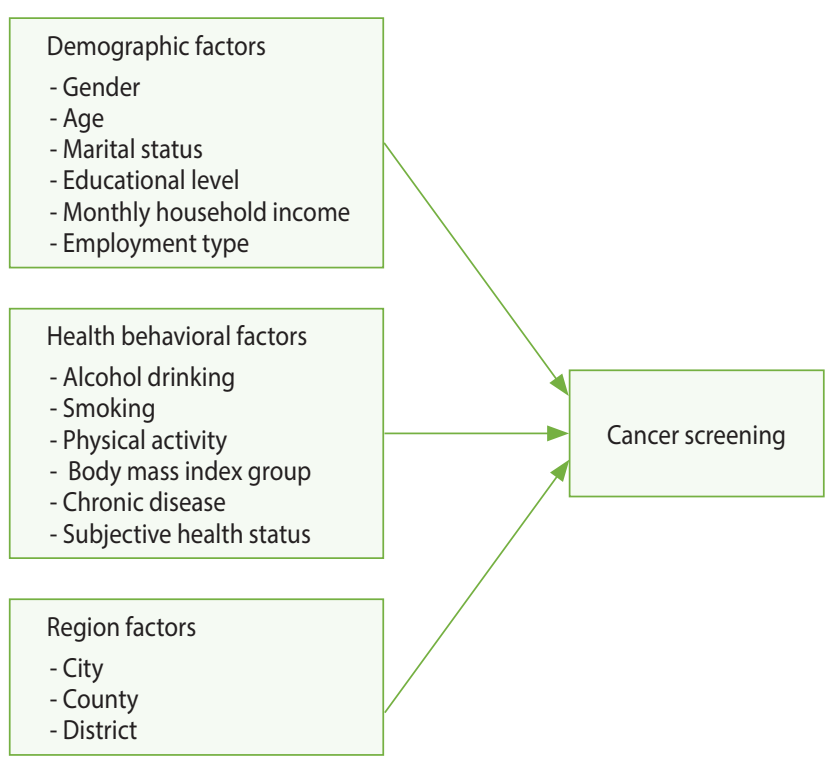

Figure 1. The conceptual model of this study.

\section{Materials and respondents}

This study based on the data from the 2014 Korean Community Health Survey (KCHS). KCHS is a Korea Centers of Disease Control and Prevention (KCDC)-sponsored survey. This survey of adults aged $\geq 19$ years conducted annually between August and October by 253 public health centers throughout Korea. Among 228,712 adults who were included in this survey, 136,627 selected for the present study after PSM and excluding 19-29 age group who were not included in the national CS program and those with missing responses or values.

\section{Variables \\ Dependent variable}

CSB was set as the dependent variable, which was divided into two categories: "yes," if the individual participated in a CS (national or private CS) in the past 2 years, and "no".

\section{Independent variables}

Demographic, health behavior, and regional characteristics were set as independent variables. The demographic characteristics include gender, age, marital status, education level, household income, and employment status $[8,11,12,14-16]$. The health behavior factors included drinking, smoking, physical activity, obesity, chronic disease, and subjective health status $[8,11,15,17]$. Regional characteristics were divided into city, county, and district. Sejong city excluded from the analysis as it might influence by confounding factors and biases $[18,19]$.

\section{Analysis method}

PSM applied to control the health behavior and regional characteristics, which may be present besides the variables of interest (demographic characteristics). Chi-square analysis performed to identify the differences between before and after PSM CSB by each factor. Additionally, logistic regression analysis performed to identify the influencing factors of CSB and their degree of influence.

\section{Propensity score matching}

This study used PSM to control any confounding factors. Generally, studies that compare two populations use non-randomized sampling design, which present problems with convenience sampling and the results being overestimated or underestimated. Accordingly, the PSM method introduced, where the variables that can act as confounding factors are preselected in the design stage and calculated as covariates to closely match the treated and control groups [20-22].

PSM analysis involved the following processes: (1) the propensity scores (PS) of the treated and control groups were estimated. The dependent variable in the present study was CSB and potential influencing health behavior factors and regional characteristics introduced as covariates to estimate the PS; (2) estimated PS were compared to create matching treated and control groups with similar PS. The study used the Greedy matching method, which uses a caliper to set a specific range of PS from the center of the 
Table 1. General characteristics of study variables by cancer screening

\begin{tabular}{|c|c|c|c|c|c|c|}
\hline \multirow{3}{*}{ Variables } & \multicolumn{6}{|c|}{ Cancer screening } \\
\hline & \multicolumn{3}{|c|}{ Before PSM } & \multicolumn{3}{|c|}{ After PSM } \\
\hline & Yes $(n=115,665)$ & No $(n=73,010)$ & $\chi^{2}$ & Yes $(n=68,336)$ & No $(n=68,336)$ & $x^{2}$ \\
\hline \multicolumn{7}{|l|}{ PS matching variables } \\
\hline \multicolumn{7}{|l|}{ Alcohol drinking } \\
\hline Current drinker & $77,853(67.3)$ & $50,813(69.6)$ & & $46,820(68.5)$ & $46,820(68.5)$ & 0.000 \\
\hline Non-drinker & $37,812(32.7)$ & $22,197(30.4)$ & $108.053^{* * *}$ & $21,516(31.5)$ & $21,516(31.5)$ & \\
\hline \multicolumn{7}{|l|}{ Smoking } \\
\hline Current smoker & $97,025(83.9)$ & $52,270(71.6)$ & $4,094.415^{* * *}$ & $51,946(76.0)$ & $51,946(76.0)$ & 0.000 \\
\hline Non-smoker & $18,640(16.1)$ & $20,740(28.4)$ & & $16,390(24.0)$ & $16,390(24.0)$ & \\
\hline \multicolumn{7}{|l|}{ Physical activity } \\
\hline Yes & $100,595(87.0)$ & $60,505(82.9)$ & $602.557^{* * *}$ & $57,181(83.7)$ & $57,181(83.7)$ & 0.000 \\
\hline No & $15,070(13.0)$ & $12,505(17.1)$ & & $11,155(16.3)$ & $11,155(16.3)$ & \\
\hline \multicolumn{7}{|l|}{ Body mass index } \\
\hline Underweight & $4,655(4.0)$ & $3,779(5.2)$ & $206.896^{* * *}$ & $3,261(4.8)$ & $3,404(5.0)$ & 3.636 \\
\hline Normal & $50,812(43.9)$ & $32,021(43.9)$ & & $30,089(44.0)$ & $30,089(44.0)$ & \\
\hline Overweight & $30,270(26.2)$ & $17,727(24.3)$ & & $16,908(24.7)$ & $16,908(24.7)$ & \\
\hline Obesity & $29,928(25.9)$ & $19,483(26.7)$ & & $18,078(26.5)$ & $17,935(26.2)$ & \\
\hline \multicolumn{7}{|l|}{ Chronic disease } \\
\hline Yes & $61,227(52.9)$ & $46,956(64.3)$ & $2,369.459^{* * * *}$ & $42,537(62.2)$ & $42,537(62.2)$ & 0.000 \\
\hline No & $54,438(47.1)$ & $26,054(35.7)$ & & $25,799(37.8)$ & $25,799(37.8)$ & \\
\hline \multicolumn{7}{|l|}{ Subjective health status } \\
\hline Healthy & $38,027(32.9)$ & $26,767(36.7)$ & $300.865^{* * *}$ & $24,472(35.8)$ & $24,615(36.0)$ & 1.124 \\
\hline Average & $51,674(44.7)$ & $31,300(42.9)$ & & $29,329(42.9)$ & $29,329(42.9)$ & \\
\hline Unhealthy & $25,964(22.4)$ & $14,943(20.5)$ & & $14,535(21.3)$ & $14,392(21.1)$ & \\
\hline \multicolumn{7}{|l|}{ Region } \\
\hline City & $33,524(29.0)$ & $21,372(29.3)$ & $102.252^{* * *}$ & $19,924(29.2)$ & $19,924(29.2)$ & 0.000 \\
\hline County & $39,911(34.5)$ & $23,638(32.4)$ & & $22,409(32.8)$ & $22,409(32.8)$ & \\
\hline District & $42,230(36.5)$ & $28,000(38.4)$ & & $26,003(38.1)$ & $26,003(38.1)$ & \\
\hline \multicolumn{7}{|l|}{ PS non-matching variables } \\
\hline \multicolumn{7}{|l|}{ Gender } \\
\hline Men & $48,819(42.2)$ & $39,166(53.6)$ & $2,352.684^{* * *}$ & $31,576(46.2)$ & $34,969(51.2)$ & $337.168^{* * *}$ \\
\hline Women & $66,846(57.8)$ & $33,844(46.4)$ & & $36,760(53.8)$ & $33,367(48.8)$ & \\
\hline \multicolumn{7}{|l|}{ Age (yr) } \\
\hline $30-39$ & $12,720(11.0)$ & $20,789(28.5)$ & $11,063.150^{* * * *}$ & $8,572(12.5)$ & $18,904(27.7)$ & $6,138.021^{* * *}$ \\
\hline $40-49$ & $26,747(23.1)$ & $16,162(22.1)$ & & $17,514(25.6)$ & $14,832(21.7)$ & \\
\hline $50-59$ & $30,763(26.6)$ & $13,297(18.2)$ & & $18,031(26.4)$ & $12,512(18.3)$ & \\
\hline $60-69$ & $24,537(21.2)$ & $9,006(12.3)$ & & $13,017(19.0)$ & $8,732(12.8)$ & \\
\hline$\geq 70$ & $20,898(18.1)$ & $13,756(18.8)$ & & $11,202(16.4)$ & $13,356(19.5)$ & \\
\hline \multicolumn{7}{|l|}{ Marital status } \\
\hline Married & $94,512(81.7)$ & $51,344(70.3)$ & $6,955.404^{* * *}$ & $55,990(81.9)$ & $48,321(70.7)$ & $3,782.788^{* * *}$ \\
\hline Separated/divorced/widowed & $17,710(15.3)$ & $12,527(17.2)$ & & $9,905(14.5)$ & $11,922(17.4)$ & \\
\hline Unmarried & $3,443(3.0)$ & $9,139(12.5)$ & & $2,441(3.6)$ & $8,093(11.8)$ & \\
\hline \multicolumn{7}{|l|}{ Educational level } \\
\hline Primary school & $30,281(26.2)$ & $16,621(22.8)$ & $1,554.073^{* * *}$ & $16,138(23.6)$ & $16,113(23.6)$ & $530.219^{* * *}$ \\
\hline Middle school & $16,724(14.5)$ & $7,689(10.5)$ & & $9,344(13.7)$ & $7,297(10.7)$ & \\
\hline High school & $36,077(31.2)$ & $23,811(32.6)$ & & $22,155(32.4)$ & $21,859(32.0)$ & \\
\hline College & $9,525(8.2)$ & $8,534(11.7)$ & & $6,060(8.9)$ & $7,817(11.4)$ & \\
\hline University & $18,936(16.4)$ & $14,024(19.2)$ & & $12,105(17.7)$ & $13,026(19.1)$ & \\
\hline Graduated school & 4,122 (3.6) & 2,331 (3.2) & & 2,534 (3.7) & $2,224(3.3)$ & \\
\hline
\end{tabular}


Table 1. Continued

\begin{tabular}{|c|c|c|c|c|c|c|}
\hline \multirow{3}{*}{ Variables } & \multicolumn{6}{|c|}{ Cancer screening } \\
\hline & \multicolumn{3}{|c|}{ Before PSM } & \multicolumn{3}{|c|}{ After PSM } \\
\hline & Yes $(n=115,665)$ & No $(n=73,010)$ & $\chi^{2}$ & Yes $(n=68,336)$ & No $(n=68,336)$ & $\chi^{2}$ \\
\hline \multicolumn{7}{|c|}{ Monthly household Income ( $\left.10^{3} \mathrm{KRW}\right)$} \\
\hline$<1,000$ & $24,719(21.4)$ & $16,129(22.1)$ & $621.613^{* * *}$ & $13,541(19.8)$ & $15,426(22.6)$ & $707.748^{* * *}$ \\
\hline $1,000-<2,000$ & $20,314(17.6)$ & $12,760(17.5)$ & & $11,419(16.7)$ & $11,940(17.5)$ & \\
\hline $2,000-<3,000$ & $20,756(17.9)$ & $15,156(20.8)$ & & $12,515(18.3)$ & $14,000(20.5)$ & \\
\hline $3,000-<4,000$ & $18,178(15.7)$ & $12,199(16.7)$ & & $11,211(16.4)$ & $11,315(16.6)$ & \\
\hline $4,000-<5,000$ & $12,643(10.9)$ & $7,277(10.0)$ & & $7,855(11.5)$ & $6,771(9.9)$ & \\
\hline$\geq 5,000$ & $19,055(16.5)$ & $9,489(13.0)$ & & $11,795(17.3)$ & $8,885(13.0)$ & \\
\hline \multicolumn{7}{|l|}{ Employment type } \\
\hline Employer and self-employed & $25,594(22.1)$ & $15,613(21.4)$ & $126.180^{* * *}$ & $15,469(22.6)$ & $14,322(21.0)$ & $102.067^{* * *}$ \\
\hline Salary & $42,680(36.9)$ & $28,815(39.5)$ & & 26,860 (39.3) & $26,327(38.5)$ & \\
\hline Inoccupation & $47,391(41.0)$ & $28,582(39.1)$ & & $26,007(38.1)$ & $27,687(40.5)$ & \\
\hline
\end{tabular}

Values are presented as number (\%).

PSM, propensity score matching; PS, propensity score; KRW, Korean won.

**** $\mathrm{p}<0.001$.

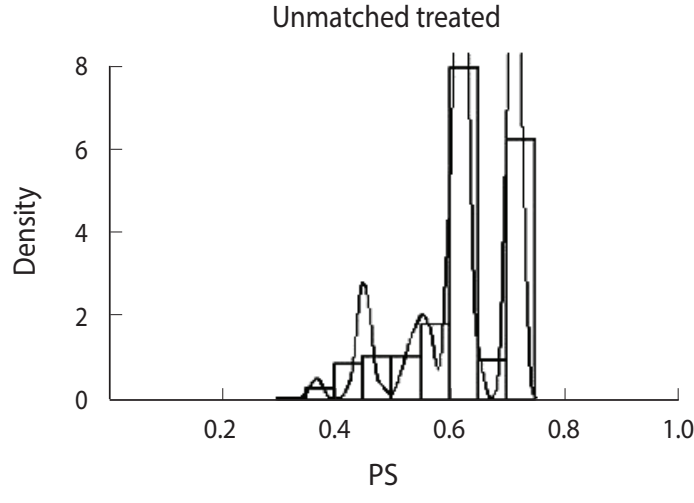

Unmatched control

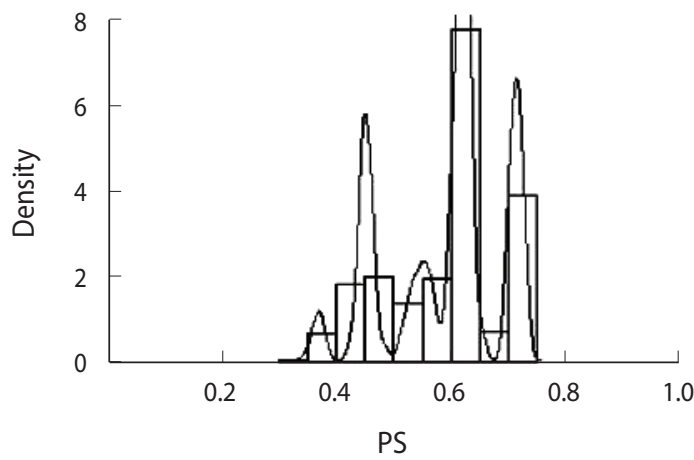

A

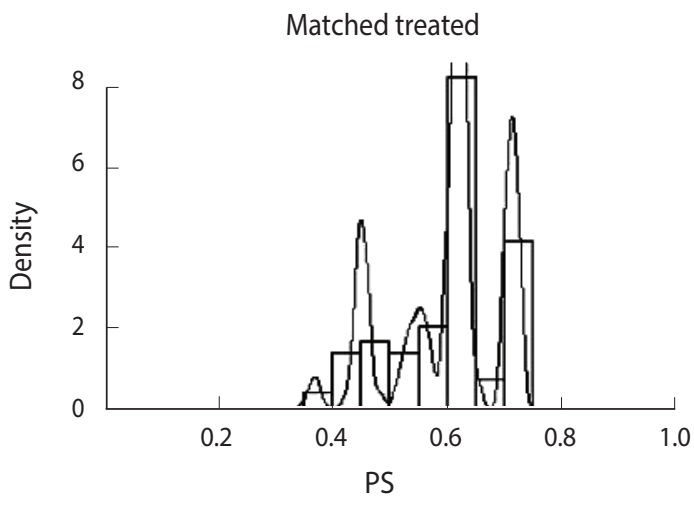

Matched control

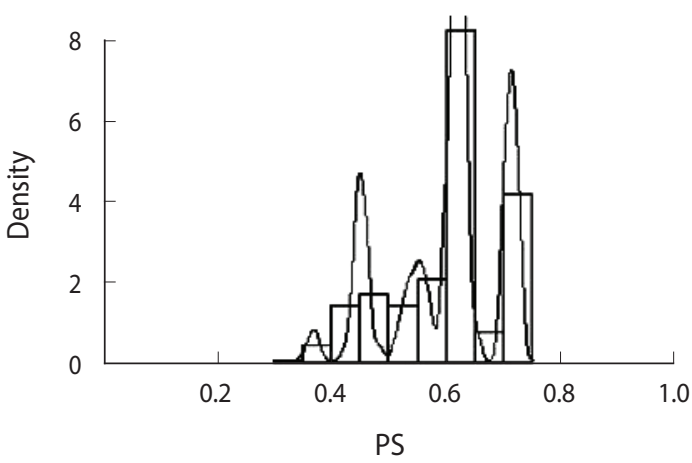

Figure 2. Comparison of propensity score (PS) distribution before and after propensity score matching, treated: cancer screening "yes", control: cancer screening "no". (A) Unmatched treated. (B) Unmatched control. (C) Matched treated. (D) Matched control.

treated group and select individuals in the control group whose scores are closest to that range [20]. Although there is no set tolerance for the caliper, 0.01-0.00001 is typically used. We used 1:1 nearest neighbor matching with a caliper of 0.0001 . As a result, 136,672 individuals were matched; (3) after performing PSM, the treated and control groups were assessed to ensure that they were 
properly matched. In this study, matching results were verified using standardized differences and graphs of the covariates in the treated and control groups. Subsequently, chi-square analysis performed on the matched individuals [23].

Table 2. Results of the logistic regression analysis

\begin{tabular}{|c|c|c|}
\hline Variables & Before PSM ${ }^{1}$ & After PSM² \\
\hline \multicolumn{3}{|l|}{ Gender (ref: women) } \\
\hline Men & $0.61(0.59,0.63)^{* * *}$ & $0.62(0.60,0.63)^{* * *}$ \\
\hline \multicolumn{3}{|l|}{ Age (ref: $\geq 70, y r$ ) } \\
\hline $30-39$ & $0.31(0.29,0.32)^{* * *}$ & $0.30(0.28,0.32)^{* * *}$ \\
\hline $40-49$ & $0.78(0.75,0.82)^{* * *}$ & $0.76(0.72,0.80)^{* * * *}$ \\
\hline $50-59$ & $1.12(1.08,1.17)^{* * *}$ & $1.07(1.03,1.12)^{* *}$ \\
\hline $60-69$ & $1.50(1.45,1.55)^{* * *}$ & $1.45(1.39,1.51)^{* * *}$ \\
\hline \multicolumn{3}{|l|}{ Marital status (ref: unmarried) } \\
\hline Married & $2.56(2.45,2.68)^{* * *}$ & $2.50(2.38,2.63)^{* * *}$ \\
\hline Separated/divorced/widowed & $1.62(1.54,1.71)^{* * *}$ & $1.62(1.53,1.72)^{* * *}$ \\
\hline \multicolumn{3}{|c|}{ Educational level (ref: graduated school) } \\
\hline Primary school & $0.65(0.61,0.69)^{* * *}$ & $0.66(0.62,0.71)^{* * *}$ \\
\hline Middle school & $0.77(0.73,0.83)^{* * *}$ & $0.78(0.73,0.84)^{* * *}$ \\
\hline High school & $0.74(0.70,0.79)^{* * *}$ & $0.75(0.70,0.80)^{* * *}$ \\
\hline College & $0.82(0.77,0.87)^{* * *}$ & $0.81(0.76,0.87)^{* * *}$ \\
\hline University & $0.87(0.82,0.93)^{* * *}$ & $0.88(0.83,0.94)^{* * * *}$ \\
\hline \multicolumn{3}{|c|}{ Monthly household income (ref: $\geq 5,000,10^{3} \mathrm{KRW}$ ) } \\
\hline$<1,000$ & $0.70(0.67,0.73)^{* * *}$ & $0.69(0.66,0.72)^{* * *}$ \\
\hline $1,000-<2,000$ & $0.73(0.70,0.76)^{* * *}$ & $0.71(0.68,0.74)^{* * *}$ \\
\hline $2,000-<3,000$ & $0.75(0.72,0.77)^{* * *}$ & $0.74(0.71,0.77)^{* * *}$ \\
\hline $3,000-<4,000$ & $0.82(0.79,0.85)^{* * *}$ & $0.81(0.78,0.85)^{* * *}$ \\
\hline $4,000-<5,000$ & $0.93(0.89,0.96)^{* * *}$ & $0.92(0.88,0.96)^{* * *}$ \\
\hline \multicolumn{3}{|c|}{ Employment type (ref: inoccupation) } \\
\hline Employer and self-employed & $1.16(1.13,1.20)^{* * *}$ & $1.15(1.12,1.19)^{* * *}$ \\
\hline Salary & $1.35(1.31,1.39)^{* * *}$ & $1.36(1.32,1.40)^{* * *}$ \\
\hline \multicolumn{3}{|l|}{ Alcohol drinking (ref: non-drinker) } \\
\hline Current drinker & $1.15(1.13,1.18)^{* * *}$ & $1.07(1.05,1.10)^{* * *}$ \\
\hline \multicolumn{3}{|l|}{ Smoking (ref: non-smoker) } \\
\hline Current smoker & $0.65(0.64,0.67)^{* * *}$ & $1.30(1.26,1.34)^{* * * *}$ \\
\hline \multicolumn{3}{|l|}{ Physical activity (ref: no) } \\
\hline Yes & $1.33(1.29,1.37)^{* * *}$ & $0.94(0.91,0.97)^{* * *}$ \\
\hline \multicolumn{3}{|l|}{ Body mass index (ref: normal) } \\
\hline Underweight & $0.91(0.87,0.95)^{* * *}$ & $1.10(1.05,1.16)^{* * *}$ \\
\hline Overweight & $1.00(0.97,1.02)$ & $0.96(0.93,0.99)^{* *}$ \\
\hline Obesity & $0.96(0.93,0.98)^{* * *}$ & $1.05(1.02,1.08)^{* * *}$ \\
\hline \multicolumn{3}{|l|}{ Chronic disease (ref: no) } \\
\hline Yes & $1.26(1.23,1.30)^{* * *}$ & $0.80(0.77,0.82)^{* * *}$ \\
\hline \multicolumn{3}{|c|}{ Subjective health status (ref: average) } \\
\hline Healthy & $0.94(0.92,0.96)^{* * *}$ & $1.02(0.99,1.05)$ \\
\hline Unhealthy & $1.01(0.98,1.04)$ & $1.11(1.07,1.14)^{* * * *}$ \\
\hline \multicolumn{3}{|l|}{ Region (ref: district) } \\
\hline City & $1.08(1.06,1.11)^{* * *}$ & $1.01(0.99,1.04)$ \\
\hline County & $1.13(1.10,1.16)^{* * *}$ & $1.00(0.98,1.03)$ \\
\hline
\end{tabular}

Values are presented as odds ratio (95\% confidence interval).

PSM, propensity score matching; KRW, Korean won.

${ }^{1} \mathrm{c}$-statistics $=0.683$, Hosmer-Lemeshow goodness-of-fit test $\mathrm{p}<0.001$.

${ }^{2} \mathrm{c}$-statistics $=0.653$, Hosmer-Lemeshow goodness-of-fit test $p<0.001$.

${ }^{* *} p<0.01,{ }^{* * *} p<0.001$. 


\section{Logistic regression analysis}

To identify the influence of demographic factors on CBS before and after PSM, a logistic regression analysis performed. PSM performed using SPSS version 23.0 (IBM Corp., Armonk, NY, USA), while logistic regression analysis was performed using SAS version 9.4 (SAS Institute Inc., Cary, NC, USA).

\section{RESULTS}

\section{Descriptive analysis of the general characteristics of the respondents}

Generally, differences noted before and after matching are analyzed to determine whether PSM produced well-matched results. Table 1 shows the results of the analysis on the differences between the characteristics of respondents before and after matching. Before matching, there were 115,665 individuals from the group who participated in CS and 73,010 from the group who did not participate. After introducing health behavior factors and regional characteristics as covariates and performing 1:1 matching by PS, results revealed a total of 68,336 matching individuals from the treated and control group. Variables that showed significant differences before matching (drinking, smoking, physical activity, obesity, chronic disease, subjective health status, and regional characteristics) did not show statistically significant differences after matching, indicating that PSM produced well-matched results.

Figure 2 shows the distribution of unmatched and matched PS of the treated and control groups as histograms for determining whether PSM produced well-matched results. The distribution of PS of the groups who did and did not participate in CS became similar after matching.

\section{Logistic regression analysis with cancer screening status as the dependent variable}

Table 2 shows the results of logistic regression analysis with CBS status before and after PSM as the dependent variable and demographic, health behavior, and regional variables as independent variables (Wald test for global null hypothesis: $\chi^{2}=6,722.866$, $\mathrm{p}<0.001$ [before PSM]; $\chi^{2}=9,516.227, \mathrm{p}<0.001$ [after PSM]). The final model was selected based on Akaike information criterion and c-statistics, but the model was determined to be unfit in the Hosmer-Lemeshow test $(\mathrm{p}<0.001)$. It is believed that HosmerLemeshow test may appear to be significant because the differences between the predicted and observed values are small with extremely large sample size [24].

In the analysis before PSM, men were less likely (39.0\%) to participate in CS, while those aged 50-69 years were more likely and 30-49 were less likely to participate in CS than those aged $\geq 70$ years. Compared to unmarried respondents, married respondents were 2.56 times, while separated, divorced, or widowed respondents were 1.62 times more likely to participate in screening. Moreover, those with lower education level and monthly income were less likely to participate in CS. Compared to being inoccupation, employers or self-employed person were 1.16 times more likely and salaried workers were 1.35 times more likely to participate in CS.

Moreover, the odds ratio (OR) of participating in CS was 1.15 and 1.33 times higher in current drinkers and people exercising, respectively, while those categorized as current smokers were $35.0 \%$ less likely to participate in CS. Relative to the normal body mass index (BMI) group, those in the underweight and obese groups were less likely to participate in CS (9.0 and 4.0\%, respectively). Those who has chronic disease were 1.26 times more likely to participate in CS. Respondents whose health status was "average" were more likely to participate in CS than those whose response was "healthy." Those who reside in a district were more likely to participate in CS than those who reside in a city or country.

In the analysis after PSM, men were less likely to participate in CS (38.0\%), while those aged 50-69 years were more likely and 3049 were less likely to participate in CS than those aged $\geq 70$ years. Compared to unmarried respondents, married respondents were 2.50 times and separated, divorced, or widowed respondents were 1.62 times more likely to participate in screening. Moreover, those with lower education level and monthly income were less likely to participate in CS. Employers or self-employed person were 1.15 times and salaried workers were 1.36 times more likely to participate in CS than unemployed people were.

Moreover, the OR of participating in CS was 1.07 and 1.30 times higher in current drinkers and current smokers, respectively, while people exercising were $6.0 \%$ less likely to participate in CS. Relative to the normal BMI group, those in the underweight and obese groups were slightly less likely to participate in CS. Those who have chronic disease were $20.0 \%$ less likely to participate. Respondents whose subjective health status was "unhealthy" were 1.11 times more likely to participate in CS than those whose response was "average."

\section{DISCUSSION}

\section{Data and method}

This study used the data from the $2014 \mathrm{KCHS}$. Previous CS studies focused mostly on a specific cancer $[11,13,14]$ or some residents in a specific region $[8,10,14,15,25]$, making it difficult to identify the factors associated with overall CS for the entire population of Korea. Accordingly, the present study was significant as it used the data from a standardized survey system that allowed comparisons between regions to examine the overall nationwide CS status.

PSM uses PS to balance the covariates observed in the respondents from each group used in the study, creating a setting similar to a randomized study [26]. This is a method that had not been widely used in previous studies on the influencing factors of CSB; thus, the present study has the advantage of minimizing selection bias and confounding factors by using PSM for a more definitive identification of the influencing factors of CSB. 


\section{Study results}

A logistic regression analysis performed before and after PSM. Smoking, chronic disease, and region showed differences before and after PSM.

The logistic regression analysis results before and after PSM were similar among demographic characteristics. In the present study, women showed higher CS rates than men, which was consistent with the results of previous studies [5,8,25,27-29], but inconsistent with other studies on the influencing factors of gastric $\mathrm{CS}$, which reported slightly higher screening rates among men $[30,31]$. This is explained by lack of time due to greater social participation by men, their lack of awareness about CS, and decrease willingness to participate in the screening. As programs included breast and cervical CS that apply only to women, women may have more opportunities to participate in the screening [25,27] Hence, CS rates among men may possibly increase if CS items include other types of cancers that only occur in men, such as prostate cancer, and actively utilize workplace screening.

Aged people were more likely to participate in CS, which was consistent with the results of previous studies [5,11,25,27,29,32]. The older people are more susceptible to chronic diseases, which increases their opportunity for healthcare utilization and in turn would increase their awareness and participation in CS as they acquire information about health management and screening [27]. Moreover, the OR of CS was relatively low among individuals aged $\geq 70$ years probably due to the low demand for and benefits from CS, which would lower the likelihood of their participation in CS [25].

With regard to marital status, most studies $[8,11,15,25,27,30$, 32-34] showed that the CS rate was higher among married individuals than those who were unmarried, a tendency that was consistent with the findings in the present study. In this study, respondents who were married as well as widowed or divorced showed higher CS rates than those who were unmarried. This may be due to the support and interest from the spouse or family members aside from being an influencing factor of CS. Respondents with lower education level and monthly household income were less likely to participate in CS, which was consistent with the results of previous studies $[8,11,15,29,30,32,33]$. Therefore, these results suggest the need for policy-based efforts to promote equality in CS.

In most studies, employment status did not show significant differences or was not included in the study at all [5,8,10,11,25,29,34]. In the present study, respondents who were employed (salaried workers, self-employed, and unpaid homemakers) were more likely to participate in CS than those who were unemployed, which was contrary to the study on cervical and breast cancers by Kim et al. [35]. The study by Kim et al. [35] was conducted only in women, whose greater time flexibility may have a greatly influenced them to participate in CS. Moreover, when targeting both men and women, improving healthcare accessibility by providing workplace screening and increasing the opportunity to acquire information about CS may influence the likelihood of participat- ing in CS.

The result of current drinking was similar and current smokers were $35.0 \%$ less likely, but 1.30 times more likely to participate in CS before and after PSM. In previous studies, health behavior factors, such as drinking and smoking, showed conflicting influence on CS $[5,28,30,33,34]$. Drinking and smoking are well-known risk factors of cancer. Because current drinkers and smokers already recognized them as undesirable health behaviors, they may have been more likely to participate in CS. These factors were successfully adjusted by PSM. Before PSM, the underweight and obese groups were less likely to participate in CS than the normal group, whereas after PSM, the same groups were more likely to participate in CS. These results were consistent with the results of Park et al. [34] and Fagan et al. [36] studies on men with colorectal and prostate cancer, but inconsistent with the results of Fagan et al. [36] study on cervical cancer. The subjects who were underweight or obese may have viewed themselves as being unhealthy, which may have increased their participation in CS.

Chronic disease and subjective health status also showed differences before and after PSM. The results after PSM were consistent with those of existing studies, which reported that patients with chronic diseases have higher healthcare utilization due to regular hospital visits, which increases their participation in CS $[8,34,36]$. This demonstrated that this factor was well adjusted. With regard to subjective health status, previous studies on CS-related factors [8], cancer survivors [27,33], and CS in South Gyeongsang Province [28] did not show significant differences. In the study, respondents whose subjective health status after PSM was categorized as "unhealthy" were 1.11 times more likely to participate in CS. It is believed that they may have participated in CS at a higher rate due to concerns about their own health.

Respondents who resided in cities or counties were more likely to participate in CS than those residing in districts before PSM, but these respondents did not show significant differences after PSM. Lack of regional disparity may be explained by the fact that because of the availability of CS at various medical institutions, the problem of healthcare accessibility may have been partially resolved [25].

The policy implications based on the findings of this study are as follows: (1) to increase the rate of participation in CS, the intention to participate in CS must be increased. CS intention can be viewed as a strong influencing factor of CSB [8]. To increase CS intention in individuals, it is important to provide education to inform the individuals on the importance of early cancer detection through screening to prevent cancer and improve the survival rate after cancer. Therefore, the rate of participation in CS should be increased by improving the personal CS intention and motivation through systematic educational programs and promotions; (2) the rate of participation in CS showed differences based on demographic factors, such as education level, monthly household income, and employment status. To resolve this disparity, it is necessary to expand the scope of free screening for most common cancers and create an environment that would make it easier for 
people to participate in CS, such as providing paid vacation time. Additionally, it is also necessary to implement CS-related promotion and education for the population with low income and low education level; and (3) since cancer is a disease that requires regular screening, it is important to increase the rate of re-screening. According to a study by Kim [37], higher patient satisfaction in CS resulted in higher cancer re-screening intention. For this, the quality of CS must be improved and the existing policies and systems must be upgraded to make them more diverse and customized based on the demographic characteristics of individuals.

The following are the limitations of this study: (1) CS status in KCHS data included national and private CS programs. As a result, the scope and characteristics of CS may vary between individuals; (2) the study used a cross-sectional survey, causality cannot be determined. In the future, it would be necessary to use cohort or panel data to investigate the causal relationships between the variables; (3) other known influencing factors of CS that were not provided in the original data could not be examined, which include family $[30,38]$ and personal history $[29,30]$ of cancer. Future studies should conduct analysis with inclusion of all known influencing factors of CS, so that these factors can be identified more clearly; (4) KCHS collected data by 1:1 interviews through home visits. Therefore, biases related demographic variables and recall bias might be introduced. Therefore, this issue should be addressed by conducting analysis that is linked to CS-related healthcare utilization and access to medical records.

The results of this study showed that gender, age, marital status, education level, household income, drinking, smoking, obesity, chronic disease, and subjective health status were the variables that influenced CSB.

CS is important for early detection of cancer to increase survival rate. Therefore, it is necessary to raise awareness about the importance of CSB through education and increase the rate of participation in CS through various promotional channels. Moreover, since cancer is a disease that requires regular screening, it is important to increase the re-screening rate, which may require development and expansion of individualized CS programs that are linked to the demographic and health behavior factors of individuals, instead of providing generic CS program.

This study is significant as it used the data that were designed to allow regional comparisons in identifying the factors influencing CSB in the entire population of Korea. Moreover, the study performed more definitive analysis by controlling any confounding factors using PSM.

\section{CONFLICT OF INTEREST}

The authors have no conflicts of interest to declare for this study.

\section{SUPPLEMENTARY MATERIALS}

Supplementary Material: Korean version is available at http:// www.e-epih.org/.

\section{ORCID}

Boyoung Choi: https://orcid.org/0000-0002-9343-4101; Tae Rim Um: https://orcid.org/0000-0003-0432-6692; Kwang-Soo Lee: https://orcid.org/0000-0003-4492-6019

\section{REFERENCES}

1. World Health Organization. Cancer; 2017 [cited 2017 Dec 28]. Available from: http://www.who.int/mediacentre/factsheets/fs297/en/.

2. Jung KW, Won YJ, Oh CM, Kong HJ, Lee DH, Lee KH, et al. Cancer statistics in Korea: incidence, mortality, survival, and prevalence in 2014. Cancer Res Treat 2017;49:292-305.

3. Statistics Korea. Cause of death 2017 [cited 2018 Jan 3]. Available from: http://www.index.go.kr/potal/stts/idxMain/selectPoSttsIdxSearch.do?idx_cd = 1012 (Korean).

4. Statistics Korea. Cause of death statistics in 2016, 2017 [cited 2017 Dec 28]. Available from: http://www.kostat.go.kr/portal/korea/ kor_nw/2/1/index.board?bmode $=$ read\&aSeq $=363268$ (Korean).

5. Roh WN, Lee WC, Kim YB, Park YM, Lee HJ, Meng KH. An analysis on the factors associated with cancer screening in a city. Korean J Epidemiol 1999;21:81-92 (Korean).

6. Jung KW, Won YJ, Kong HJ, Oh CM, Shin A, Lee JS. Survival of Korean adult cancer patients by stage at diagnosis, 2006-2010: national cancer registry study. Cancer Res Treat 2013;45:162-171.

7. World Health Organization. Cancer prevention [cited 2018 Jan 21]. Available from: http://www.who.int/cancer/prevention/en/.

8. Kwak MS, Park EC, Bang JY, Sung NY, Lee JY, Choi KS. Factors associated with cancer screening participation, Korea. J Prev Med Public Health 2005;38:473-481 (Korean).

9. Suh M, Song S, Cho HN, Park B, Jun JK, Choi E, et al. Trends in participation rates for the national cancer screening program in Korea, 2002-2012. Cancer Res Treat 2017;49:798-806.

10. Kim YB, Lee WC. A study on the behavioral factors related to stomach cancer screening among adults in a rural area. Korean J Epidemiol 1999;21:20-30 (Korean).

11. Lee $\mathrm{MH}, \mathrm{Kim} \mathrm{SH}$. Breast cancer screening rates-related factors Korea women ever considering area environmental characteristics: the fourth Korea National Health and Nutrition Examination Survey (KNHANES IV). J Digit Converg 2014;12:437-449 (Korean).

12. Cho IS, Park YS. A study on regular cervical cancer screening behavior among middle-aged women. J Korean Acad Nurs 2004; 34:141-149 (Korean).

13. Ham OK. Analysis of factors related to mammography screening behavior women: use of health belief model. J Korean Public Health Nurs 2004;18:187-194 (Korean).

14. Kim YI, Cho YC. The associated factors of health examinations behaviors among some elderly persons in urban and rural areas. J Agric Med Community Health 2004;29:1-14 (Korean).

15. Kim MK, Nam EW, Jin KN. The factors influencing the odds of cancer examination in Wonju city. Korean J Health Educ Promot 2006;23:85-97 (Korean). 
16. Lee JW, Ahn SY, Kim KH. Study on factors that influence cancer screening rate in urban and rural areas. J Digit Converg 2012;10: 269-278 (Korean).

17. Jeong GB, Park JY, Kwon SY, Park KO, Park PS, Park MY. A comparison between asia-pacific region criteria and entropy model criteria about body mass index of elderly females using morbidity of chronic disease. Korean J Community Nutr 2014;19:490-498 (Korean).

18. Shin SD. It came to the health checkup season: where are the citizens of Sejong? Goodmorning Chungcheong; 2015 Nov 25 [cited 2017 Dec 9]. Available from http://www.goodmorningcc.com/ news/articleView.html?idxno $=34693$ (Korean).

19. Yoon S. Sejong city health center conducts cancer screening and health check-up. Aju Business Daily; 2015 Feb 8 [cited 2017 Feb 9]. Available from http://www.ajunews.com/view/201502082115 30589 (Korean).

20. Kim SY, Baek JI. FUZZY matching using propensity score: IBM SPSS 22 Ver. J Korean Data Inf Sci Soc 2016;27:91-100 (Korean).

21. Austin PC. Propensity-score matching in the cardiovascular surgery literature from 2004 to 2006: a systematic review and suggestions for improvement. J Thorac Cardiovasc Surg 2007;134:11281135.

22. Choi SJ, Kim SS. The analysis for effect on government R\&D subsidies by using PSM. J Korea Acad Ind Coop Soc 2009;10:200208 (Korean).

23. Seo EW, Lee KS. Difference in healthcare utilization for percutaneous transluminal coronary angioplasty inpatients by insurance types: propensity score matching analysis. Health Policy Manag 2015;25:3-10 (Korean).

24. Feudtner C, Hexem KR, Shabbout M, Feinstein JA, Sochalski J, Silber JH. Prediction of pediatric death in the year after hospitalization: a population-level retrospective cohort study. J Palliat Med 2009;12:160-169.

25. Sung NY, Park EC, Shin HR, Choi KS. Participation rate and related socio-demographic factors in the national cancer screening program. J Prev Med Public Health 2005;38:93-100 (Korean).

26. Jang EJ, Ahn J, Jung SY, Hwang JS, Lee JY, Shim JI. Methods for the control of measured confounders in outcomes research. Seoul: National Evidence-based Healthcare Collaborating Agency; 2013, p. 1-272 (Korean).

27. Yang SE, Han NK, Lee SM, Kim TH, Chung W. The factors relat- ed to the non-practice of cancer screening in cancer survivors: based on the 2007-2012 Korean National Health and Nutrition Examination Survey. Health Policy Manag 2015;25:162-173 (Korean).

28. Kim RB, Park KS, Hong DY, Lee CH, Kim JR. Factors associated with cancer screening intention in eligible persons for national cancer screening program. J Prev Med Public Health 2010;43:6272 (Korean).

29. Cullati S, Charvet-Bérard AI, Perneger TV. Cancer screening in a middle-aged general population: factors associated with practices and attitudes. BMC Public Health 2009;9:118.

30. Kim HK. Influence of socioeconomic status and health behavior with cancer screening program [dissertation]. Seoul: Yonsei University; 2006 (Korean).

31. Shin JY, Lee DH. Factors associated with the use of gastric cancer screening services in Korea: the fourth Korea National Health and Nutrition Examination Survey 2008 (KNHANES IV). Asian Pac J Cancer Prev 2012;13:3773-3779.

32. Kwon YM, Lim HT, Lee K, Cho BL, Park MS, Son KY, et al. Factors associated with use of gastric cancer screening services in Korea. World J Gastroenterol 2009;15:3653-3659.

33. Cho J, Guallar E, Hsu YJ, Shin DW, Lee WC. A comparison of cancer screening practices in cancer survivors and in the general population: the Korean National Health And Nutrition Examination Survey (KNHANES) 2001-2007. Cancer Causes Control 2010;21:2203-2212.

34. Park JD, Kang PS, Lee KS. Factors related with screening behaviors of breast and cervical cancers among women in a rural area. J Korean Soc Matern Child Health 2001;8:49-64 (Korean).

35. Kim YB, Ro WO, Lee WC, Park YM, Meng KH. The influence factors on cervical and breast cancers screening behavior of women in a city. J Korean Soc Health Educ Promot 2000;17:1-16 (Korean).

36. Fagan HB, Wender R, Myers RE, Petrelli N. Obesity and cancer screening according to race and gender. J Obes 2011;2011:218250.

37. Kim HJ. Factors influencing cancer rescreening intention of Korean elderly. Korean J Rehabil Nurs 2015;18:118-127 (Korean).

38. Bostean G, Crespi CM, McCarthy WJ. Associations among family history of cancer, cancer screening and lifestyle behaviors: a population-based study. Cancer Causes Control 2013;24:14911503. 